\title{
Analisis Kinerja Virtual Router Redudancy Protocol (VRRP) Di Mikrotik Router Pada Dirjen Sumber Daya Air Balai Besar Wilayah Sungai Sumatera VIII
}

\author{
Alhimni \& Ilman Zuhri Yadi \\ Fakultas Ilmu Komputer, Universitas Bina Darma \\ Email : alhimny95@gmail.com
}

\begin{abstract}
This research is based on the observations and experiences of researchers, that now the internet has become a basic need for an agency, almost all Directorates of Water Resources (SDA) have a computer network. The Directorate of Water Resources (SDA) Central Sumatra River Basin VIII has implemented a network to support the performance of the Directorate of Water Resources (SDA), but still has problems where the network often experiences disconnections due to damage, interference with switches, damage to cables and network connectors. and Hang routers. To meet the internet needs at the Directorate of Water Resources (SDA) Central Sumatra VIII River Basin, stable internet is needed, therefore a failover method is needed. The problem in this research is that there are frequent disturbances in the internet network. The transfer of the main internet line to the backup path is done manually. Given how important the network is to support performance at the Directorate of Water Resources (SDA), the authors suggest to create a failover backup system for Mikrotik routers in the Directorate of Water Resources (SDA). This research uses the Action Research development method, which consists of Diagnostic, Action planning, action taking, evaluating and e-learning. With this application, it is hoped that if there is a problem with the router device, it will not interfere with the use of the existing network. On the internet network of the Directorate of Water Resources (SDA) Central Sumatra River Region VIII.
\end{abstract}

Keywords : Faillover, VRRP, Mikrotik

\section{Pendahuluan}

Direktorat Sumber Daya Air (SDA) Balai Besar Wilayah Sungai Sumatera VIII telah menerapkan jaringan komputer dengan menjalankan router mikrotik untuk membantu berbagai system operasi external dan akan semakin bertambahnya mengikuti kepentingan system pada Direktorat Sumber Daya Air (SDA), namun masih memiliki kendala didalam koneksi jaringan karena belum ada linkbackup router, jika terjadi permasalahan pada router sedangkan link backup router tidak tersedia maka akan berpengaruh pada semua perangkat yang terkoneksi ke jaringan, dan jika terjadi permasalahan pada router proses komunikasi antar client atau komunikasi server dengan client tidak dapat dilakukan. Mengingat betapa pentingnya peran dari router dalam menunjang operasi di Direktorat Sumber Daya Air (SDA) Balai Besar Wilayah Sungai Sumatera VIII, dimana semua hardware harus terkoneksi dengan internet dan bisa di update setiap saat. Pentingnya sistem link backup router dan kebutuhan di objek penelitian, maka penulis mengambil judul tentang “Analisis Kinerja Virtual Router Redudancy Protocol (VRRP), Pada Mikrotik Router di Balai Besar Wilayah Sungai Sumatera VIII", guna meningkatkan koneksi internet pada Direktorat Sumber Daya Air (SDA) dan bisa berjalan dengan efektif, sehingga tidak terjadi downtime koneksi iternet dan mempercepat dalam memperbaikan router primary.

Penerapan VRRP yang digunakan diantara dua router, memungkinkan router cadangan 
untuk mengganti router utama dengan segera tanpa menunggu waktu yang ditentukan, dengan biaya yang dikeluarkan cukup efektif untuk penerapkan metode ini. Tujuan pada penelitian ini adalah untuk membuat sebuah sistem Failover pada perangkat gateway yaitu router, jika terjadi permasalahan pada router maka akan ada router yang akan langsung mengantikan router tersebut, dengan menggunakan metode action researchdan diharapkan jika terjadi permasalahan pada perangkat router maka tidak akan menggangu penggunaan jaringan yang ada.

\section{Tinjauan Literatur}

\subsection{Jaringan Komputer}

Dalam karya ilmiah, (Alfurqon \& Assegaff, 2018) Jaringan komputer ini sangat di manfaatkan dalam dunia bisnis, hingga system belajar mengajar jaringan komputer merupakan kumpulan dari perangkat keras dan lunak di dalam suatu sistem yang memiliki aturan tertentu untuk mengatur seluruh anggotanya dalam melakukan aktivitas komunikasi. Satu komputer yang terkoneksi ke jaringan menjadi satu node dari jaringan tersebut. Sedangkan host secara umum diartikan sebagai komputer yang terkoneksi kejaringan yang dapat memberikan layanan jaringan (network service).

\subsection{Pengertian Redundant}

Redundancy adalah jalur jaringan alternatif yang digunakan untuk meningkatkan ketersediaan jaringan, sehingga jika dalam suatu jaringan terdapat link yang terputus maka jalur untuk data masih bisa terhubung tanpa mempengaruhi konektivitas perangkat pada jaringan tersebut, (Mukmin \& Negara, 2019). Secara sederhana konsep redundancy link merupakan cara kita mempersiapkan jalur baru sebagai bentuk kesiapan kita apabila jalur utama pada koneksi jaringan kita terputus sehingga jalur koneksi internet tetap bias berjalan melalui jaringan backup yang telah kita buat sebelumnya. Redundant Link berfungsi untuk menghindari terjadinya kegagalan jaringan.

\subsection{Downtime}

Pada dasarnya downtime didefinisikan sebagai waktu suatu komponen system tidak dapat digunakan (tidak berada dalam kondisi yang baik), sehingga membuat fungsi system tidak berjalan. Berdasarkan kenyataan bahwa pada dasarnya prinsip utama dalam manajemen perawatan adalah untuk menekan periode kerusakan sampai batas minimum, maka keputusan penggantian komponen system berdasarkan downtime minimum menjadi sangat penting, (Choirullah et al., 2016).

\subsection{Delay}

Delay adalah waktu tunda sebuah proses pengiriman data dari satu titik sumber ke titik tujuan. Seperti di jalan raya jika dalam perjalanan ada hal-hal yang terjadi tidak terduga maka akan membuat proses perjalanan kita terganggu alias tidak sesuai target. Hal ini mungkin dalam perjalanan seringnya menjumpai lampu merah, maka perjalanan akan tertunda dari target yang diinginkan. Dalam jaringan internet sering terjadi delay pada saat media transmisi mengalami kestabilan, (Amarudin \& Riskiono, 2019).

\subsection{Failover}

Dalam karya ilmiah, (Firmansyah, Wahyudi, M \& Rachmat, 2018) Failover jaringan merupakan teknik yang menerapkan beberapa jalur untuk mencapai suatu network tujuan. 
Namun dalam keadaan normal hanya ada satu link yang digunakan. Link yang lain berfungsi sebagai cadangan dan hanya akan digunakan bila link utama terputus[7] Failover jaringan merupakan teknik yang menerapkan beberapa jalur untuk mencapai suatu network tujuan. Namun dalam keadaan normal hanya ada satu link yang digunakan. Link yang lain berfungsi sebagai cadangan dan hanya akan digunakan bila link utama terputus.

\subsection{Throughput}

Throughput adalah bandwidth aktual yang terukur pada suatu ukuran waktu tertentu dalam suatu hari menggunakan rute internet yang spesifik ketika sedang men download suatu file.

\section{Rumus Throughput $=$ Jumlah bandwidth}

$$
\text { Waktu pengiriman }
$$

\subsection{Axence Net tools}

Axence Net Tools merupakan salah satu tool solusi yang bagus untuk mengukur kinerja jaringan dan cepat mendiagnosis masalah jaringan. Komponen unggulan Net Watch grafis yang disertai dengan waktu respon dan paket yang hilang (untuk memantau ketersediaan host Anda). Axence Net Tools ini juga memiliki tools popular lainnya trace, lookup, port scanner, network scanner, dan SNMP browser, (Amarudin, 2018).

\subsection{Virtual Router Redundancy Protocol (VRRP)}

Menurut jurnal (Choirullah et al., 2016), merupakan salah satu teknik yang digunakan untuk mempertahankan link dengan menerapkan sistem cadangan. Ketika sebuah router yang bertindak sebagai router master mengalami gangguan, maka $V R R P$ akan mengatur mekanisme perutean paket data sehingga paket data akan dialihkan melalui router lain yang disebut router backup.

\subsection{Routing Protocol}

Routing Protocol adalah suatu protokol yang digunakan untuk mendapatkan rute atau petunjuk dari satu jaringan ke jaringan yang lain, routing merupakan proses dimana suatu router akan memilih jalur atau rute untuk mengirimkan atau meneruskan suatu paket ke jaringan yang dituju, (Sujalwo, 2011). Router menggunakan IP address tujuan untuk mengirimkan packet, dan agar router mengetahui rute mana yang harus digunakan untuk meneruskan packet ke alamat tujuan, router harus belajar atau bertukar informasi sesama router yang saling terhubung untuk mengetahui jalur atau rute yang terbaik.

\subsection{Konfigurasi}

Konfigurasi adalah pengaturan atau proses pembuatan pengaturan dari bagianbagian yang membentuk keseluruhan. Dalam komputer dan jaringan komputer, konfigurasi sering mengacu pada hardware spesifik dan rincian perangkat lunak dalam hal perangkat yang terpasang, kapasitas atau kemampuan, pada sistem yang 14 dibuat. Dalam jaringan, konfigurasi sering berarti topologi jaringan dan Dalam menginstal hardware dan software, konfigurasi kadang-kadang proses metodis mendefinisikan pilihan yang disediakan, (Isador, 2019).

\section{Metode Penelitian}




\subsection{Diagnosing}

Pada tahap ini dilakukan identifikasi terhadap sumber masalah yang ada pada infrastruktur jaringan di Direktorat Sumber Daya Air (SDA) Balai Besar Wilayah Sungai Sumatera VIII. Perusahaan telah menerapkan jaringan komputer berbasis LAN untuk membantu berbagai sistem operasi internal dan akan semakin bertambah mengikuti kepentingan system pada Direktorat Sumber Daya Air (SDA) Balai Besar Wilayah Sungai Sumatera VIII, namun masih memiliki kendala didalam koneksi jaringan karena belum ada linkbackup router, jika terjadi permasalahan pada router sedangkan link backup router tidak tersedia maka akan berpengaruh pada semua perangkat yang terkoneksi ke jaringan, dan jika terjadi permasalahan pada router proses komunikasi antar client atau komunikasi server dengan client tidak dapat dilakukan. Berikut adalah data jaringa yang terdapat pada Direktorat :

\begin{tabular}{|c|c|c|c|c|}
\hline No. & Time & Source & Destination & Protocol \\
\hline 1 & 40 & 192.168 .100 .254 & 192.168 .100 .254 & ICMP \\
\hline 2 & 183 & 192.168 .100 .1 & 192.168 .100 .254 & ICMP \\
\hline 3 & 104 & 192.168 .100 .17 & 192.168 .100 .254 & ICMP \\
\hline 4 & 52 & 192.168 .100 .34 & 192.168 .100 .254 & ICMP \\
\hline 5 & 36 & 192.168 .100 .22 & 192.168 .100 .254 & ICMP \\
\hline 6 & 46 & 192.168 .100 .51 & 192.168 .100 .254 & ICMP \\
\hline
\end{tabular}

\subsection{Action Planning}

Pada Tahap ini peneliti harus memiliki perencanaan yang sudah terencana sedari awal untuk menentukan hasil yang lebih optimal, peneliti akan melakukan rencana pembentukan topologi jaringan baru mengganti data IP serta melakukan konfigurasi jaringan menggunakan HSRP sebagai jalur backup untuk melakukan implementasikan redudancy link pada infrastruktur jaringan di Direktorat Sumber Daya Air (SDA) Balai Besar Wilayah Sungai Sumatera VIII.

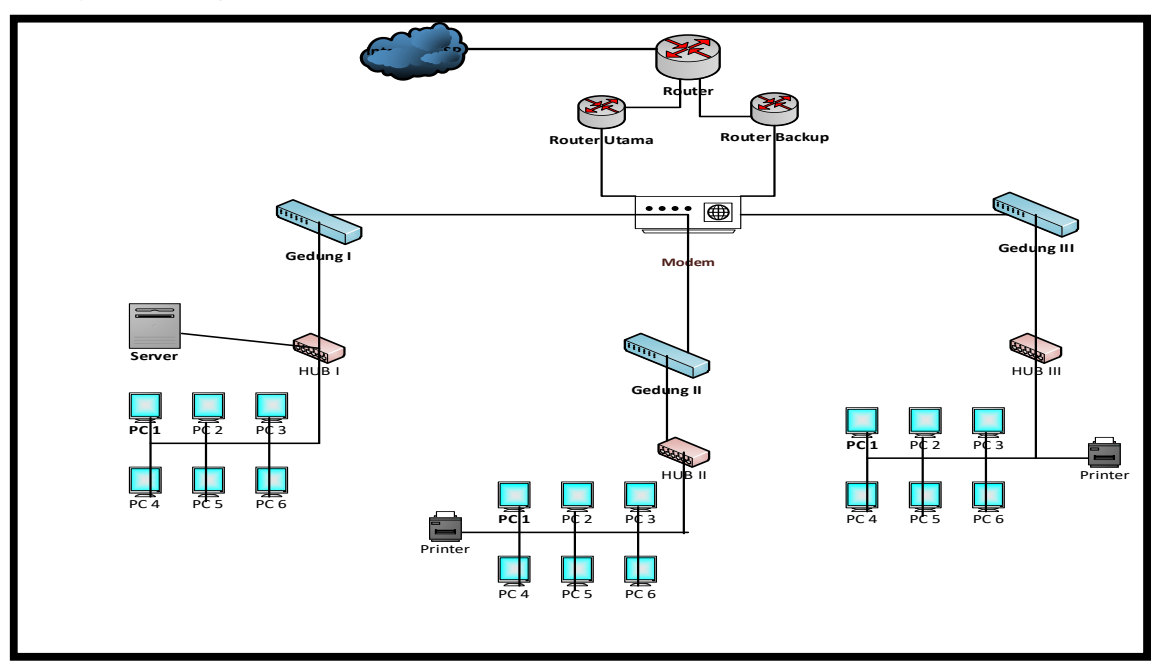


Gambar 3.1 Topology Yang Ditawarkan

Sumber : Direktorat Sumber Daya Air (SDA) Balai Besar Wilayah Sungai Sumatera VIII

\section{Hasil dan Pembahasan}

Berdasarkan hasil dari penerapan dalam Analisis Kinerja Virtual Router Redudancy Protocol (Vrrp) Di Mikrotik Router Pada Dirjen Sumber Daya Air Balai Besar Wilayah Sungai Sumatera VIII menurut peneliti merasa sudah berjalan dengan lancar sesuai rangkaian perencanaan dari awal, dimana dengan adanya router backup jaringan pada peruhaan menjadi lebih stabil dan tidak selalu mengalami kegagalan atau down pada jaringan, sehingga dapat membantu memaksimalkan dalam proses pekerjaan seluruh kariawan yang berhubungan dengan network. Kebutuhan suatu jaringan untuk menyediakan layanan yang lebih baik pada trafik data tertentu pada berbagai jenis platfrom teknologi disebut quality of service (QOS). Beberapa parameter yang mempengaruhi QOS antara lain delay, packet loss dan trouughput. Oleh karena itu untuk meningkatkan kualitas layanan jaringan maka harus sesuai dengan parameter QOS. Dan untuk mempertahankan tingakat kualitas layanan nerwork yang dibutuhkan dan meminimalisir kegagalan dalam sebuah perangkat network maka perlu ada beberapa perangkat network yang dapat mengambil alih dari perangkat utama yang mengalami kegagalan atau lebih dikenal dengan nama redundant.

Berdasarkan data failover pada Tabel 4.4 dan Tabel 4.5 dalam pengujian router ketika dimatikan backup failover dari masing masing routerterdapat data sebagai berkut :

\begin{tabular}{|c|c|c|}
\hline Pengujian & Failover router utama & Failover Router Backup \\
\hline uji coba 1 & 0.03 .14 & 0.03 .09 \\
\hline uji coba 2 & 0.02 .58 & 0.03 .05 \\
\hline uji coba 3 & 0.03 .06 & 0.03 .12 \\
\hline uji coba 4 & 0.06 .20 & 0.03 .20 \\
\hline uji coba 5 & 0.02 .04 & 0.07 .04 \\
\hline uji coba 6 & 0.03 .00 & 0.02 .05 \\
\hline uji coba 7 & 0.03 .12 & 0.03 .12 \\
\hline uji coba 8 & 0.03 .08 & 0.03 .08 \\
\hline uji coba 9 & 0.02 .48 & 0.03 .12 \\
\hline uji coba 10 & 0.03 .20 & 0.03 .20 \\
\hline
\end{tabular}




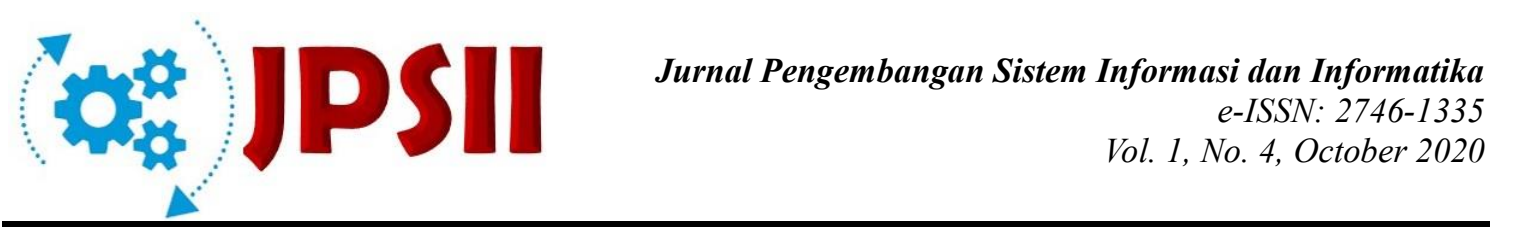

\begin{tabular}{|c|c|c|} 
uji coba 11 & 0.03 .01 & 0.04 .05 \\
\hline uji coba 12 & 0.02 .56 & 0.02 .56 \\
\hline uji coba 13 & 0.03 .06 & 0.02 .04 \\
\hline uji coba 14 & 0.04 .01 & 0.06 .01 \\
\hline uji coba 15 & 0.03 .08 & 0.03 .08 \\
\hline uji coba 16 & 0.03 .30 & 0.02 .59 \\
\hline uji coba 17 & 0.03 .15 & 0.03 .15 \\
\hline
\end{tabular}

Maka kesimpulan yang dihasilkan failover yang dilakukan oleh Routerutama lebih cepat dibandingkan router backup ketika terjadi kondisi down pada jaringan dengan perbedaan backup sekitar 12 detik lebih cepat router backup dari pada router utama dengan hasil rata rata failover yang didapat kita bisa simpulkan bahwa jaringan baik utama maupun jaringan backup memiliki time failover jaringan yaitu 3 sampai 4 menit. dengan waktu tersebut ketersediaan jaringan pada Direktorat Sumber Daya Air (SDA) Balai Besar Wilayah Sungai Sumatera VIII lebih baik dan lebih efisien. sehingga hasil nya mampu mengurangi waktu downtime pada jaringan yang sebelumnya. ketika jaringan down membutuhkan waktu 20 sampai 35 menit, namun sekarang waktu ketersediaan jaringan memiliki waktu yang cukup cepat yaitu 3 sampai 4 menit. sehingga apabila di persentase kan data failover jaringan pada masing masing router dari aktif ke backup maupun sebaliknya dari data sebelumnya 30 menit ke 3 menit didapat keefektivan waktu lebih cepat 27 menit atau 97\% dalam bentuk persentase. Persentase tersebut didapat dengan melakukan rumus perhitungan berikut. 30 menit $=100 \%$ sedangkan 27 menit $=97 \%$ artinya perbedaan dari 30 menit ke 3 menit sama dengan 27 menit. maka didapat persentase waktu perpindahan dari router utama ke backup maupun sebaliknya mengalami kenaikan 97\%. Melihat hasil sebelum dan sesudah dilakukan penerapan redundancy jaringan menggunakan $H S R P$ menjadi perbandingan jaringan sebelum diterapkan nya jaringan redudant sebagai redundancy jaringan dan jaringan yang telah di perbaharui menggunakan HSRP, Sebelum diterapkannya redundancy jaringan hanya terdapat satu class IP tanpa ada nya pembagian VLAN sehingga trafik semua user langsung masuk ke satu server.

Adapun pengecekan yang dilakukan yaitu pengecekan traffic jaringan yang ada menggunakan aplikasi Axence Nettools sebagai berikut.

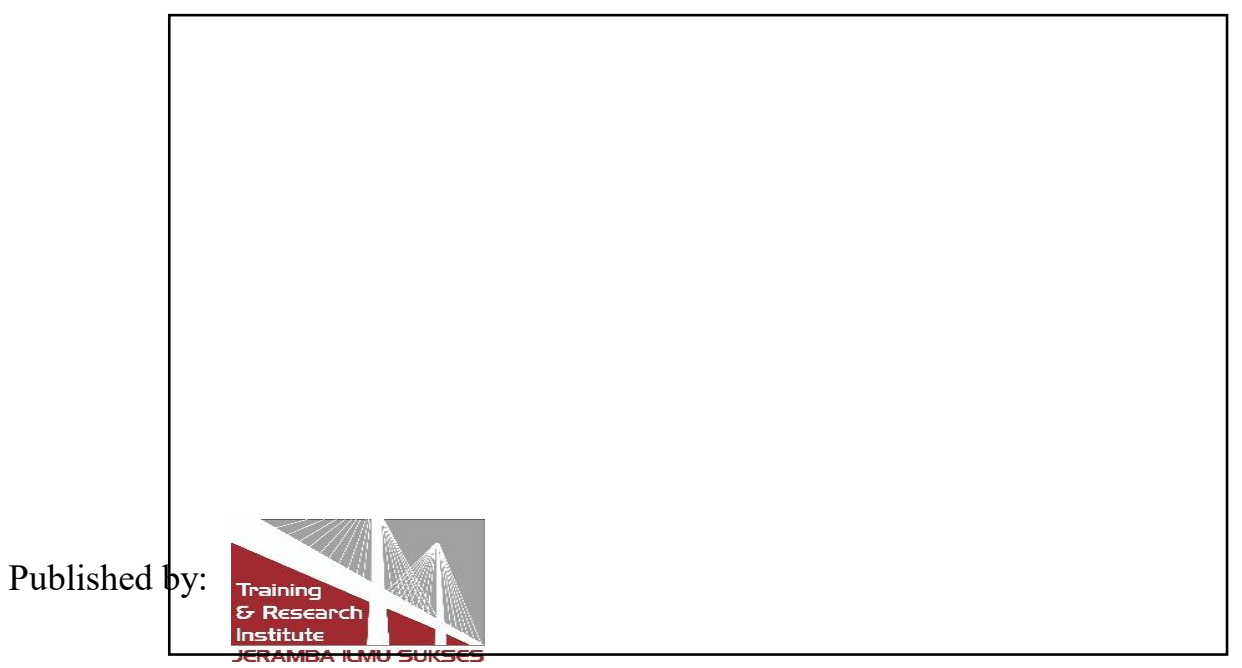




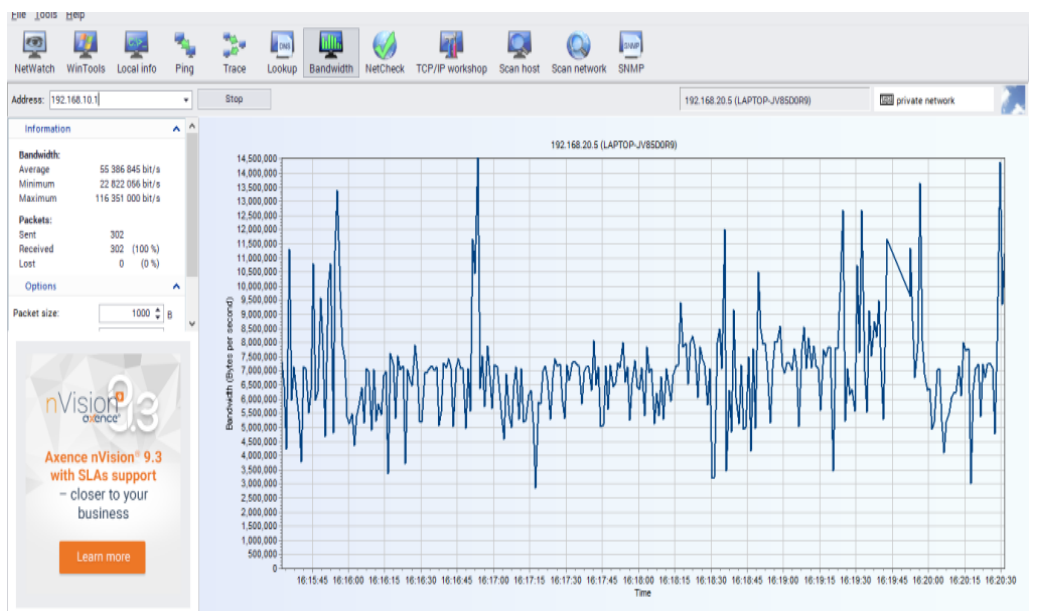

Gambar 4.6 Trafik jaringan ketika single link

Berdasarkan grafik diatas menunjukan kepadatan jaringan yang sangat banyak dimana trafik pada jaringan terlalu padat ketika dilakukan ping masal dari ke 10 pc sehingga memberatkan kinerja jaringan. Sehingga memberatkan kinerja router jika dilakukan hanya menggunakan single link pada jaringan .trafik diatas diambil sebelum dilakukan redundancy link pada jaringan untuk melakukan perbandingan pada masing masing trafik jaringan.

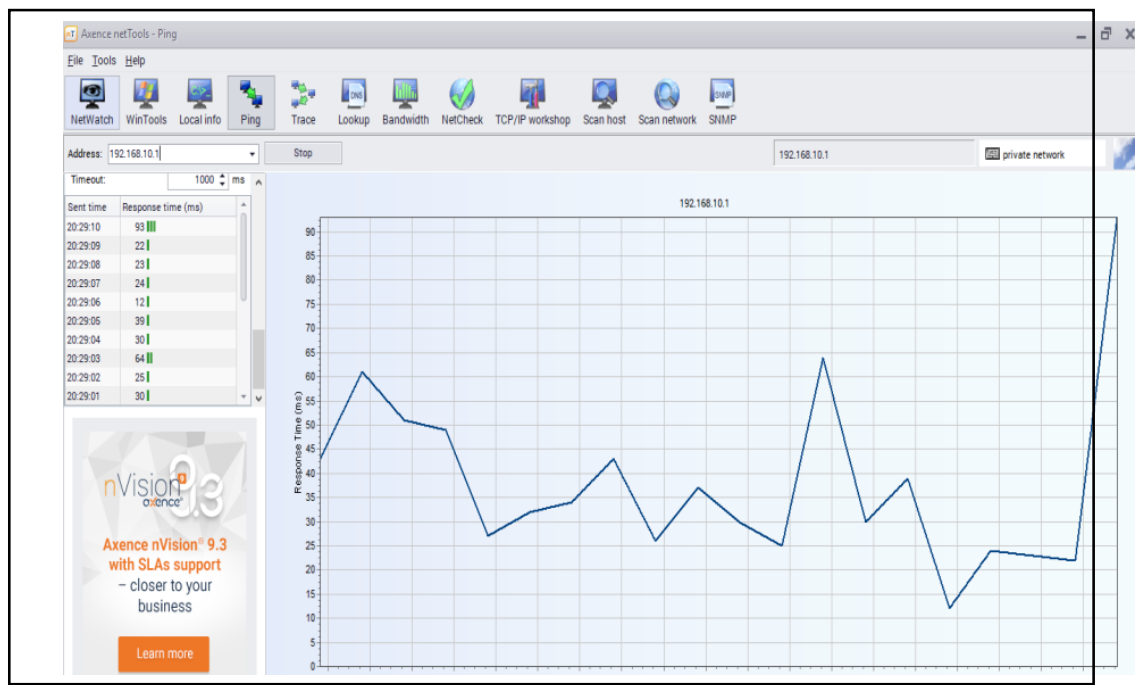

Gambar 4.7 Trafik jaringan sesudah di terapkan nya redundant link

Berdasarkan grafik diatas menunjukan kehandalan jaringan yang sangat efektif dimana trafik yang tadi nya terlalu padat ketika dilakukan ping masal dari ke 10 pc sehingga memberatkan kinerja jaringan kini sudah membaik dimana trafik jaringan yang telah diperbaiki memiliki trafik yang cukup longgar dikarenakan setiap $I P$ yang ingin melakukan koneksi terbagi menjadi 2 jalur yaitu jalur VLAN 10 dan jalur VLAN20. Maka dari itu trafik pada perlunya pembagian segmentasi $I P$ pada tiap tiap $P C$ agar tidak memberatkan beban koneksi ke server. Adapun tabel perbandingan topologi lama dengan topologi baru sebagai berikut.

Tabel 4.10 Perbandingan Topologi Jaringan Lama Dan Topologi Jaringan Baru 


\begin{tabular}{|c|c|c|}
\hline Perbandingan & Topologi Lama & Topologi Baru \\
\hline HSRP & Tidak Ada & Ada \\
\hline Segmentasi & Tidak Ada & 2 \\
\hline Jalur Redudancy & Tidak Ada & Ada \\
\hline Pembagian Jalur Trafic & Tidak Ada & Ada \\
\hline Management & Sulit & Mudah \\
\hline
\end{tabular}

Berdasarkan Perbandingan topologi yang lama dan topologi yang baru pada Tabel 4.10 diatas dilihat dari segi fitur, segmentasi jalur redundancy dan management topologi yang baru lebih unggul

Tabel 4.11 Perbandingan Delay sebelum dan sesudah dilakukan redundant link

\begin{tabular}{|c|c|c|}
\hline No & Delay lama & Delay baru \\
\hline 1 & 235 & 131 \\
\hline 2 & 270 & 95 \\
\hline 3 & 280 & 130 \\
\hline 4 & 315 & 127 \\
\hline 5 & 350 & 110 \\
\hline 6 & 124 & 120 \\
\hline 7 & 158 & 78 \\
\hline 8 & 100 & 184 \\
\hline 9 & 115 & 161 \\
\hline 10 & 94 & 82 \\
\hline 11 & 109 & 81 \\
\hline 12 & 147 & 109 \\
\hline 13 & 134 & \\
\hline 14 & 176 & 161 \\
\hline
\end{tabular}




\begin{tabular}{|l|l|r|}
\hline \multicolumn{3}{|c|}{$\begin{array}{r}\text { Jurnal Pengembangan Sistem Informasi dan Infor } \\
\text { e-ISSN: 274 } \\
\text { Vol. 1, No. 4, October }\end{array}$} \\
\hline 15 & 113 & 85 \\
\hline 16 & 104 & 95 \\
\hline 17 & 89 & 79 \\
\hline
\end{tabular}

Berdasarkan perbandingan delay lama dan delay baru yang terjadi sebelum dan sesudah dilakukan redundant link pada jaringan didapat lah hasil perubahan delay yang cukup signifikan pada jaringan sehingga membuat koneksi internet semkain stabil pada jaringan

Tabel 4.14 Perbandingan Jitter sebelum dan sesudah dilakukan redundant link

\begin{tabular}{|c|c|c|}
\hline No & Jitter lama & Jitter baru \\
\hline 1 & 36 & 36 \\
\hline 2 & 44 & -35 \\
\hline 3 & 38 & 3 \\
\hline 4 & 39 & 17 \\
\hline 5 & 40 & -10 \\
\hline 6 & 41 & 42 \\
\hline 7 & 42 & -106 \\
\hline 8 & 43 & 23 \\
\hline 9 & 44 & 12 \\
\hline 10 & 45 & 79 \\
\hline 11 & 46 & 1 \\
\hline 12 & 47 & -28 \\
\hline 13 & 48 & -29 \\
\hline 14 & 49 & 53 \\
\hline 15 & 50 & -10 \\
\hline 16 & 52 & -10 \\
\hline
\end{tabular}


Berdasarkan perbandingan Jitter lama dan Jitter baru yang terjadi sebelum Jitter yang cukup signifikan pada jaringan sehingga membuat koneksi internet semkain stabil pada jaringan.

\section{Kesimpulan}

Pada penelitian ini penulis telah mengimplementasi redundan link dengan metode failover untuk mengatasi kegagalan link pada jaringan, maka dari itu dapat diambil kesimpulan sebagai berikut :

1. Pengujian yang telah dilakukan pada jaringan menunjukan peningkatan kualitas jaringan dengan pengujian failover pada jaringan didapatkan waktu tidak sampai 10 menit untuk melakukan backup pada setiap ruangan.

2. Penerapan redundancy link memberikan efek yang sangat signifikan dalam menekan waktu downtime pada jaringan yang sebelumnya ketika down menghabiskan waktu 20-30 menit kini rata rata waktu hanya 3 menit untuk kembali aktif.

3. Penerapan redundancy link yang saat ini telah diterapkan akan gagal jika terjadi pemadaman listrik Pada Dirjen Sumber Daya Air Balai Besar Wilayah Sungai Sumatera VIII.

\section{Referensi}

Antoni, D., Herdiansyah, M. I., Akbar, M., \& Sumitro, A. (2021). Pengembangan Infrastruktur Jaringan Untuk Meningkatkan Pelayanan Publik di Kota Palembang. JURNAL MEDIA INFORMATIKA BUDIDARMA, 5(4), 1652-1659.

Antoni, D., Jie, F., \& Abareshi, A. (2020). Critical factors in information technology capability for enhancing firm's environmental performance: case of Indonesian ICT sector. International Journal of Agile Systems and Management, 13(2), 159-181.

Antoni, D., \& Akbar, M. (2019). E-supply chain management value concept for the palm oil industry. Jurnal Sistem Informasi, 15(2), 15-29.

Antoni, D., Fikari, D., \& Akbar, M. (2018). The readiness of palm oil industry in enterprise resource planning. Telkomnika, 16(6), 2692-2702.

Fauzi, F., Dencik, A. B., \& Asiati, D. I. (2019). Metodologi Penelitian untuk manajemen dan akuntansi. Jakarta: Salemba Empat.

Achmad Solichin, S. K. (2008). Pemrograman Web dengan PHP dan MySQL.

Amiruddin, R., \& HS, M. A. (2017). Perancangan Proxy Server Dengan Menggunakan Squid Di Cv. Nusantara Geotech Makassar. Jurnal Instek (Informatika Sains Dan Teknologi), 2(2), 51-60. https://doi.org/10.24252/instek.v2i2.4017

Choirullah, M.Y., Anif, M., Rochadi, A., 2016. Analisis Kualitas Layanan Virtual Router Redundancy Protocol Menggunakan Mikrotik pada Jaringan VLAN. J. Nas. Tek. Elektro Dan Teknol. Inf. JNTETI 5. https://doi.org/10.22146/jnteti.v5i4.275

Christanto, F. W., \& Suprayogi, M. S. (2017). Rancangan Network Monitoring System Untuk Pemantauan Sumber Daya Virtual Server Pada Jaringan Cloud Computing Universitas Semarang. Simetris : Jurnal Teknik Mesin, Elektro Dan Ilmu Komputer, 329- 
334. https://doi.org/10.24176/simet.v8i2.1555

Prasandy, T., \& Adhiwibowo, W. (2015). Virtualisasi Server Sederhana Menggunakan $\begin{array}{llll}\text { Proxmox. Jurnal Transformatika, } & \text { 12(2), }\end{array}$ https://doi.org/10.26623/transformatika.v12i2.80

Pamungkas, W.H., Prayitno, E., 2018. Perancangan Jaringan Redundancy Link Menggunakan Konsep Hsrp Dan Etherchannel 2, 8.

Prasetyo, I. (2013). Simulasi dan Monitoring DHCP. 1-21.

Saputra, A., \& Syafrizal, M. (2012). Perancangan Dan Implementasi Mail Server Pada Cv. Sanjaya Anugerah Sejahtera (Isp Jogjaringan) Berbasis Open Source. Data Manajemen Dan Teknologi Informasi (DASI), 13(2), 1.

Wahyudi, M., Purnama, R.A., 2018. Analisis Perbandingan Kinerja Jaringan CISCO Virtual Router Redundancy Protocol (VRRP) Dan CISCO Hot Standby Router Protocol (HSRP) 6.

\section{Copyrights}

Copyright for this article is retained by the author(s), with first publication rights granted to the journal.

This is an open-access article distributed under the terms and conditions of the Creative Commons Attribution license (http://creativecommons.org/licenses/by/4.0/) 